DOI: $10.18027 / 2224-5057-2021-11-3 s 2-39$

Цитирование: Сакаева Д.Д., Борисов К.Е., Булавина И.С., Когония Л.М., Курмуков И.А., Орлова Р.В. и соавт. Практические рекомендации по диагностике и лечению фебрильной нейтропении. Злокачественные опухоли : Практические рекомендации RUSSCO \#3s2, 2021 (том 11). 39

\title{
ПРАКТИЧЕСКИЕ РЕКОМЕНДАЦИИ ПО ДИАГНОСТИКЕ И ЛЕЧЕНИЮ ФЕБРИЛЬНОЙ НЕЙТРОПЕНИИ
}

Коллектив авторов: Сакаева Д.Д., Борисов К.Е., Булавина И.С., Когония Л.М., Курмуков И.А., Орлова Р.В., Шабаева М.М.

Ключевые слова: поддерживающая терапия, противоопухолевая терапия, нежелательное явление, фебрильная нейтропения, антибиотикотерапия, колониестимулирующие факторы

Фебрильная нейтропения (ФН) - неотложное состояние, опасное нежелательное явление противоопухолевой терапии, ведущее к увеличению общей летальности и возрастанию расходов на лечение онкологических больных. При современном лекарственном противоопухолевом лечении развитие ФН прогнозируется у 7,9-11,7\% пациентов с атрибутивной летальностью до $11 \%$.

ФН диагностируется в том случае, когда у пациента с нейтропенией развивается фебрильная лихорадка (D70 по МКБ-10). Под нейтропенией понимают уровень нейтрофилов периферической крови $\leq 500$ клеток в мкл, либо $\leq 1000$ клеток в мкл, если в течение следующих 2 суток вероятно их снижение до $\leq 500$ клеток в мкл. В исключительных случаях недоступности определения лейкоцитарной формулы ориентиром может служить количество лейкоцитов $\leq 1000$ клеток в мкл.

Фебрильная лихорадка подразумевает хотя бы однократное повышение температуры тела, эквивалентное $\geq 38,3^{\circ} \mathrm{C}$ при измерении во рту или прямой кишке (соответствует $\geq 38,1^{\circ} \mathrm{C}$ при измерении в подмышечной впадине), либо повышение температуры тела, эквивалентное $\geq 38,0^{\circ} \mathrm{C}$ при измерении во рту или прямой кишке (соответствует $\geq 37,8^{\circ} \mathrm{C} п р и$ измерении в подмышечной впадине), сохраняющееся в течение $\geq 1$ часа.

В $90 \%$ случаев основной причиной ФН у пациентов с солидными опухолями является бактериальная инфекция. Эмпирическая терапия всегда должна быть направлена на элиминацию бактериальной инфекции.

\section{1. ДИАГНОСТИКА И ОЦЕНКА РИСКОВ НЕБЛАГОПРИЯТНОГО РАЗВИТИЯ ФН}

Обязательное обследование при $Ф \mathrm{H}$, направленное на оценку тяжести состояния и определение причин лихорадки, включает: 
- опрос, осмотр и полное физикальное обследование пациента;

- общеклинический анализ крови с определением лейкоцитарной формулы;

- биохимическое исследование крови с определениемглюкозы, креатинина, Алт, альбумина, натрия и калия;

- бактериологическое исследование крови из периферической вены (исследование подразумевает одновременное использование 2-х сред обогащения, аэробной и анаэробной). Если во время развития ФН у пациента уже имеется сосудистый доступ, кровь на стерильность берется и через него (если сосудистый доступ многопросветный, то через каждый отдельный просвет), одновременно с кровью из периферической вены и аналогичным образом.

Необходимость и объем дополнительныхисследований определяется врачом в соответствии с данными анамнеза, выявляемыми симптомами, доступностью отдельных методов исследования. При наличии лабораторных возможностей, особенно в период сезонного роста заболеваемости ОРВИ, целесообразно исследование мазков из носо-и ротоглотки на вирусные антигены наиболее частых возбудителей (как правило, методом флюоресцирующих антител). В соответствии с действующими локальными или временными правилами обязательной может быть проверка и на иные инфекции: во время работы над настоящими рекомендациями, например, это исследование мазков из носо-и ротоглотки на наличие вирусной PHK SARS-CoV-2 (методом ПЦР).

При тяжелом общем состоянии пациента показана экстренная госпитализация и дальнейшее лечение в условиях круглосуточного стационара. В остальных случаях оценивается наличие факторов риска неблагоприятного развития ФН. С этой целью используются два прогностических индекса, MASCC и CISNE, позволяющие ранжировать пациентов в группы различного риска. Тяжелое течение заболевания предполагается при индексе риска MASCC $<21$ или CISNE $\geq 3$ (табл. 1,2).

Таблица 1. Шкала MASCC-score и интерпретация результата

\begin{tabular}{|l|l|}
\hline Показатель и критерий его оценки & Балл \\
\hline Общая выраженность симптомов ФН (сепсиса): нет или легкие/умеренные/тяжелые & $5 / 3 / 0$ \\
\hline АДсист >90 мм рт ст: да/нет & $5 / 0$ \\
\hline Без ХОБЛ: да/нет & $4 / 0$ \\
\hline Без инвазивного микоза в анамнезе: да/нет & $4 / 0$ \\
\hline Без дегидратации: да/нет & $3 / 0$ \\
\hline Лихорадка появилась не во время госпитализации: да/нет & $3 / 0$ \\
\hline Возраст младше 60 лет: да/нет & $2 / 0$ \\
\hline Интерпретация результата & Сумма 6аллов \\
\hline $\begin{array}{l}\text { Низкий риск (дополнительные тяжелые осложнения 8-12\%, 28-дневная летальность 1\%; } \\
\text { в отдельных случаях возможно амбулаторное лечение) }\end{array}$ & 21 \\
\hline Высокий риск (подразумевает госпитализацию) & $16-20$ \\
\hline Крайне высокий риск (подразумевает лечение в ОРИт) & $\leq 15$ \\
\hline
\end{tabular}


Таблица 2. Шкала CISNE-score и интерпретация результата

\begin{tabular}{|c|c|}
\hline Показатель и критерий его оценки & Балл \\
\hline ECOG-PS $\geq 2$ & 2 \\
\hline Стресс-индуцированная гипергликемия & 2 \\
\hline Хроническое обструктивное заболевание легких & 1 \\
\hline Хроническое кардиоваскулярное заболевание & 1 \\
\hline Мукозит $\geq 2$ степени по СТСАЕ & 1 \\
\hline Моноциты < 200 кл в мкл & 1 \\
\hline Интерпретация результата (вероятность смерти) & Сумма баллов \\
\hline $\begin{array}{l}\text { Низкий риск (28-дневная летальность 1\%; в отдельных случаях возможно } \\
\text { амбулаторное лечение) }\end{array}$ & 0 \\
\hline Высокий риск (подразумевает госпитализацию) & $1-2$ \\
\hline 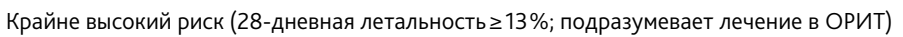 & $3-8$ \\
\hline
\end{tabular}

Другими важными неблагоприятными прогностическими факторами являются:

- длительность ФН до начала антибиотикотерапии более 1 суток;

- предполагаемая продолжительность нейтропении более 7 дней;

- выявление очага инфекции и соответствующая ему клиническая картина (высокая вероятность сепсиса);

- острое нарушение или декомпенсация функции жизненно-важных органов (высокая вероятность дальнейшего прогрессирования нарушений).

Наличие любого из перечисленных факторов является показанием к лечению пациента в условиях круглосуточного стационара, а клиническая нестабильность и острое нарушение или декомпенсация функции жизненно-важных органов - к госпитализации в отделение с расширенными возможностями круглосуточного наблюдения и прикроватного мониторинга (палата интенсивной терапии, отделение реанимации и интенсивной терапии).

Если риск (по шкалам MASSC и CISNE) оценивается как низкий, а другие факторы тяжелого течения или неблагоприятного исхода ФН отсутствуют, дальнейшее лечение может быть организовано в рамках как стационарной, так и амбулаторно-поликлинической помощи. Амбулаторное лечение возможно при условии хорошего контакта с пациентом, постоянного контроля за его состоянием и возможности обеспечения ухода со стороны близких, при необходимости - немедленной связи (для дополнительной консультации врачом и коррекции лечения) и быстрой транспортировки в клинику. Лучший контроль (в том числе лабораторный) обеспечивает лечение в условиях стационара на дому (медицинский патронаж) или дневного стационара. При сомнениях в качестве ухода на дому или иных проблемах, снижающих безопасность, пациенту следует предлагать лечение в условиях круглосуточного стационара. 


\section{2. ЭМПИРИЧЕСКАЯ АНТИБИОТИКОТЕРАПИЯ}

Антибиотикотерапия является основным методом лечения $\Phi$; раннее начало, достаточная доза и кратность введения антибиотиков позволяют уменьшить период лихорадки, снизить тяжесть проявлений (в том числе обусловленных инфекцией органных повреждений) и атрибутивную летальность, увеличивают вероятность своевременного продолжения противоопухолевого лечения.

Эмпирическая антибиотикотерапия должна быть инициирована как можно раньше, обычно сразу после забора крови на бактериологическое исследование. При первом в ведении антибиотик широкого спектра действия в достаточной дозе (рекомендуется использовать высшую разовую дозу препарата) вводится внутривенно.

\section{1. Антибиотики, прием внутрь}

Могут назначаться пациентам, способным принимать препараты внутрь, получающим лечение амбулаторно и не получавшим фторхинолоны в последние 6 недель, например:

- моксифлоксацин (по 0,4 годин раз в день);

- левофлоксацин (по 0,5 г каждые 12 часов или по 0,75г один раз в день) и амоксициллин/клавуланат (по 0, 875/0,175 г каждые 8 часов или 1,0/0,25 г каждые 12 часов);

- ципрофлоксацин (по 0,75г каждые 12 часов) и амоксициллин/клавуланат (по 0,875/0,175 г каждые 8 часов или 1,0/0,25 г каждые 12 часов);

- ципрофлоксацин (по 0,75г каждые 12 часов) и клиндамицин (по 0,3 г каждые 8 часов).

\section{2. Антибиотики, парентеральное введение}

В отсутствии индивидуальных противопоказаний (например, аллергии) или применения пациентом аналогичного антибактериального средства в последние 6 недель, рекомендуется назначение бета-лактамных антибиотиков широкого спектра действия с высокой активностью в отношении псевдомонад, как правило, в режиме монотерапии, например:

- цефепим (по 2,0 г каждые 8 часов, внутривенно);

- имипенем/циластатин (по 0,5 г каждые 6 часов, внутривенно);

- меропенем (по 1,0 г каждые 8 часов, внутривенно);

- пиперациллин/тазобактам (по 4,5 г каждые 6 часов, внутривенно).

При аллергии на бета-лактамные антибиотики могут использоваться комбинированные схемы, например, азтреонам (по 2,0 г каждые 8 часов, внутривенно) и ванкомицин (по 1,0 г каждые 12 часов, внутривенно).

\section{3. Особые варианты антибиотикотерапии - ФН с выявляемым очагом инфекции}

При выявлении очага инфекции предпочтительно проведение комбинированной антибиотикотерапии: бета-лактамный антибиотик широкого спектра действия с высокой 
активностью в отношении псевдомонад +антибиотик с активностью в отношении возбудителей, характерных для соответствующего очага:

- при катетер-ассоциированной инфекции - ванкомицин;

- при инфекции кожи, мягких тканей и пневмонии - линезолид;

- при мукозите и энтероколите - амикацин (15-20 мг/кг/сутки внутривенно) и/или метронидазол (по 0,5 г каждые 6 часов внутривенно).

Подробный анализ рациональной антибиотикотерапии иных очаговых проявлений бактериальной инфекции выходит за рамки настоящих рекомендаций; в таких случаях эмпирический выбор препаратов и режима их дозирования должен основываться на конкретной клинической ситуации, данных локальных эпидемических исследований и, как правило, является предметом междисциплинарного обсуждения.

\section{3. КОНТРОЛЬ ЭФФЕКТИВНОСТИ ЛЕЧЕНИЯ}

Эффективность эмпирической антибиотикотерапии при ФН определяется контролем фебрильной лихорадки. В большинстве случаев раннего назначения антибиотиков широкого спектра действия и отсутствия очага персистирующей инфекции (например, инфицированного венозного доступа, очаговой пневмонии, абсцесса) контроль над лихорадкой достигается в первые 24 часа, а полный контроль - в первые 48 часов лечения. При полном контроле лихорадки показанием к прекращению антибиотикотерапии является отсутствие признаков инфекции и уровень нейтрофилов периферической крови выше 1000 клеток в мкл. Необходимо помнить, что выявление некоторых возбудителей требует длительного применения антибиотиков даже при полном восстановлении уровня нейтрофилов (например, 3-4 недели при инфекции кровотока, вызванной Staphylococus aureus); подробную информацию можно найти в соответствующих руководствах.

Если лихорадка сохраняется дольше 72 часов на фоне эмпирической антибиотикотерапии, требуется повторное обследование, в том числе бактериологическое. Необходимо повторно оценить возможное наличие очага инфекции (в том числе и любого имплантированного пациенту устройства), рассмотреть клиническую целесообразность использования методов визуализации (например, ЭхоКГ для исследования клапанов сердца, КТ грудной клетки или органов брюшной полости и т. д.). Амбулаторным пациентам рекомендуется госпитализация в круглосуточный стационар; если пациент первоначально получал лечение антибиотиками для приема внутрь, их следует отменить и назначить один из вариантов эмпирической внутривенной антибиотикотерапии. Если к этому времени получен положительный результат первичного бактериологического исследования крови, следует провести коррекцию антибиотикотерапии в соответствии с чувствительностью выявленного возбудителя (антибиотикограммы). В отсутствие положительного результата бактериологического исследования крови полезный ориентир может дать исследование биохимических маркеров бактериальной (прокальцитонин) и грибковой (галактоманнан) инфекций. Если общее состояние не ухудшается до анализа результатов повторного обследования, то необходимости в эскалации эмпирической антибиотикотерапии, как правило, 
нет. При ухудшении общего состояния, прогрессировании органных нарушений - вариант интенсификации лечения следует выбрать по результатам междисциплинарного обсуждения с привлечением специалистов, имеющих более глубокие знания и клинический опыт в области интенсивной терапии и госпитальной инфекции.

\section{4. ПРИМЕНЕНИЕ Г-КСФ ДЛЯ ПРОФИЛАКТИКИ И ЛЕЧЕНИЯ ФН}

Применение препаратов Г-КСФ, уменьшающее продолжительность нейтропении и/или ее глубину, может оказаться полезным методом профилактики или, в отдельных случаях, лечения ФН. Общими правилами являются:

- Г-КСФ назначается не ранее, чем через 24 часа по окончании химиотерапии, а прекращается не позднее, чем за 48 часов до начала следующего курса.

- Введение Г-КСФ продолжается ежедневно до достижения желаемого уровня нейтрофилов периферической крови (как правило, не выше 10000 кл в мкл).

- Г-КСФ не применяются для лечения афебрильной нейтропении, при осложнениях и инфекциях, не связанных с нейтропенией (например, внутрибольничная пневмония), а также не назначаются при отсутствии факторов высокого риска развития ФН.

\section{1. Первичная профилактика ФН}

Первичная профилактика целесообразна либо при высоком прогнозируемом риске $Ф Н$, либо при существенных негативных последствиях $Ф \mathrm{H}$ :

- при нозологияхи режимах противоопухолевого лечения с высоким риском развития ФН (табл. 3);

- истощении (малом резерве) костного мозга, в том числе у пациентов старше 65 лет, или вследствие повторных курсов противоопухолевого лечения;

- для обеспечения оптимальной интенсивности лечения в тех случаях, когда редукция доз цитостатиков может негативно влиять на выживаемость.

Первичная профилактика Г-КСФ не рекомендуется при ХЛТ с облучением органов грудной клетки (возможно, увеличивает частоту ФН и общую летальность).

\section{2. Вторичная профилактика ФН}

Пациентам, ранее пережившим ФН, при последующем противоопухолевом лечении профилактическое введение Г-КСФ целесообразно при более чем $10 \%$ вероятности повторного эпизода (табл. 4), в том числе, когда по соображениям противоопухолевой эффективности, изменение протокола лечения и редукция доз противоопухолевых препаратов нежелательны. В настоящее время в клинической практике используются Г-КСФ короткого и пролонгированного действия (табл. 5). 
Таблица 3. Нозологии и режимы химиотерапии с высоким (>20\%) риском развития ФН

\begin{tabular}{|c|c|}
\hline Нозология & Режим \\
\hline Рак мочевого пузыря & $\begin{array}{l}\text { M-VAC (метотрексат, винбластин, доксорубицин, цисплатин), ddM-VAC } \\
\text { Паклитаксел, цисплатин }\end{array}$ \\
\hline Рак молочной железы & $\begin{array}{l}\text { Дозо-уплотнённые режимы АС/P (доксорубицин, циклофосфамид/пакли- } \\
\text { таксел } 1 \text { раз в } 2 \text { нед.) } \\
\text { ТСН (доцетаксел + карбоплатин + трастузумаб) }\end{array}$ \\
\hline Рак шейки матки & Паклитаксел, цисплатин \\
\hline $\begin{array}{l}\text { Немелкоклеточный рак } \\
\text { лёгкого }\end{array}$ & Доцетаксел, карбоплатин \\
\hline $\begin{array}{l}\text { Мелкоклеточный рак } \\
\text { лёгкого }\end{array}$ & Циклофосфамид, доксорубицин, этопозид \\
\hline Саркомы & $\begin{array}{l}\text { Доксорубицин, ифосфамид, дакарбазин } \\
\text { VAI (винкристин, доксорубицин, ифосфамид) } \\
\text { Доксорубицин, цисплатин } \\
\text { IA (доксорубицин, ифосфамид) } \\
\text { IE-VAC (ифосфамид, этопозид-винкристин, доксорубицин, циклофосфамид) } \\
\text { GEMTAX (гемцитабин, доцетаксел) }\end{array}$ \\
\hline Рак яичников & Топотекан 1,5 мг/м² (1-5-й дни) \\
\hline Опухоли яичка & $\begin{array}{l}\text { PEI (этопозид, ифосфамид/+ месна, цисплатин) } \\
\text { TIP (паклитаксел, ифосфамид/+ месна, цисплатин) } \\
\text { VEIP (винбластин, ифосфамид/+ месна, цисплатин) }\end{array}$ \\
\hline Рак головы и шеи & $\begin{array}{l}\text { TIP (паклитаксел, ифосфамид/+ месна, цисплатин) } \\
\text { DCF (доцетаксел+ цисплатин + фторурацил) }\end{array}$ \\
\hline Рак желудка & DCF (доцетаксел, фторурацил, цисплатин \\
\hline Колоректальный рак & FOLFOXIRI (фолинат кальция, фторурацил, оксалиплатин, иринотекан) \\
\hline Рак поджелудочной железы & FOLFIRINOX (фолинат кальция, фторурацил, оксалиплатин, иринотекан) \\
\hline
\end{tabular}

Таблица 4. Нозологии и режимы химиотерапии с вероятностью развития ФН 10-20\%

\begin{tabular}{|l|l|}
\hline Вид опухоли & Режим \\
\hline Рак молочной железы & АС, доцетаксел, паклитаксел 175 мг/м² \\
\hline Рак шейки матки & Цисплатин + топотекан, цисплатин + паклитаксел, топотекан, иринотекан \\
\hline Колоректальный рак & FOLFOX6 \\
\hline Рак желудка & $\begin{array}{l}\text { ECF (эпирубицин, цисплатин, фторурацил), ECX (эпирубицин, цисплатин, } \\
\text { капецитабин), иринотекан + цисплатин }\end{array}$ \\
\hline $\begin{array}{l}\text { Немелкоклеточный рак } \\
\text { легкого }\end{array}$ & $\begin{array}{l}\text { Цисплатин + доцетаксел, цисплатин + винорелбин, цисплатин + этопозид, } \\
\text { цисплатин+ паклитаксел, доцетаксел, карбоплатин + паклитаксел }\end{array}$ \\
\hline Мелкоклеточный рак легкого & Этопозид+ карбоплатин \\
\hline Рак яичников & Доцетаксел+ карбоплатин \\
\hline Рак предстательной железы & Кабазитаксел \\
\hline Рак матки & Доцетакел \\
\hline
\end{tabular}




\section{3. Применение колониестимулирующих факторов для лечения фебрильной нейтропении}

В общей популяции пациентов с ФН использование Г-КСФ статистически значимо снижает длительность нейтропении на 1-2 дня, не сокращает продолжительность лихорадки и длительность АБ терапии в случае развития ФН и не снижает стоимости лечения одного эпизода ФН.

Однако Г-КСФ могут принести пользу отдельным пациентам, при лечении которых длительность и глубина нейтропении могут иметь решающее значение, в частности при сочетании глубокой нейтропении и выраженных симптомов инфекции, сохраняющихся на фоне активной многокомпонентной антибиотикотерапии.

Таблица 5. Рекомендуемые гранулоцитарные колониестимулирующие факторы

\begin{tabular}{|c|c|c|c|}
\hline $\mathrm{MHH}$ & Фармакологические свойства & Форма выпуска & $\begin{array}{l}\text { Режим дозирования } \\
\text { и введения }\end{array}$ \\
\hline \multicolumn{4}{|c|}{ Пролонгированные формы } \\
\hline Эмпэгфилграстим & $\begin{array}{l}\text { Ковалентный коньюгат } \\
\text { филграстима с одной молекулой } \\
\text { полиэтиленгликоля, пролонгиро- } \\
\text { ванного действия }\end{array}$ & $\begin{array}{l}\text { Раствор } \\
\text { для п/к введения }\end{array}$ & $\begin{array}{l}\text { 7,5 мг (без учета массы тела) } \\
\text { п/к однократно не менее } \\
\text { чем через } 24 \text { часа после } \\
\text { окончания введения химио- } \\
\text { препаратов }\end{array}$ \\
\hline Липэгфилграстим & $\begin{array}{l}\text { Гликопегилированный Г-КСФ } \\
\text { пролонгированного действия }\end{array}$ & $\begin{array}{l}\text { Раствор } \\
\text { для п/к введения }\end{array}$ & $\begin{array}{l}6 \text { мг (без учета } \\
\text { массы тела) п/к однократно } \\
\text { через } 24 \text { ч после каждого } \\
\text { цикла ХТ }\end{array}$ \\
\hline Пэгфилграстим & $\begin{array}{l}\text { Рекомбинантный пегилиро- } \\
\text { ванный Г-КСФ (филграстим), } \\
\text { конъюгированный с полиэтилен- } \\
\text { гликолем, пролонгированного } \\
\text { действия }\end{array}$ & $\begin{array}{l}\text { Раствор } \\
\text { для п/к введения }\end{array}$ & $\begin{array}{l}6 \text { мг (без учета массы тела) } \\
\text { однократно п/к не ранее чем } \\
\text { через } 24 \text { часа и не позднее } \\
14 \text { суток после курса ХТ }\end{array}$ \\
\hline \multicolumn{4}{|l|}{ Обычные формы } \\
\hline Филграстим & $\begin{array}{l}\text { Рекомбинантный человеческий } \\
\text { негликолизированный Г-КСФ }\end{array}$ & $\begin{array}{l}\text { Раствор } \\
\text { для п/к и в/в вве- } \\
\text { дения }\end{array}$ & $\begin{array}{l}5 \text { мкг/кг массы тела } \\
1 \text { раз/сутки п/к или в/в еже- } \\
\text { дневно через 24-72 часа } \\
\text { после последнего дня ХТ } \\
\text { до необходимого стабиль- } \\
\text { ного АЧН }\end{array}$ \\
\hline Ленограстим & $\begin{array}{l}\text { Рекомбинантный человеческий } \\
\text { гликолизированный Г-КСФ }\end{array}$ & $\begin{array}{l}\text { Лио- } \\
\text { филизированное } \\
\text { сухое вещество } \\
\text { для п/к и в/в инъ- } \\
\text { екций во флако- } \\
\text { нах в комплекте } \\
\text { с растворителем }\end{array}$ & $\begin{array}{l}\text { 19,2 млн. МЕ (или } 150 \text { мкг) } \\
\text { на м² поверхности тела } \\
\text { (0,64 млн. МЕ или } 5 \text { мкг } \\
\text { на кг массы тела) в день } \\
\text { п/к или в/в ежедневно } \\
\text { через 24-72 часа после } \\
\text { последнего дня ХТ до необ- } \\
\text { ходимого стабильного АЧН }\end{array}$ \\
\hline
\end{tabular}




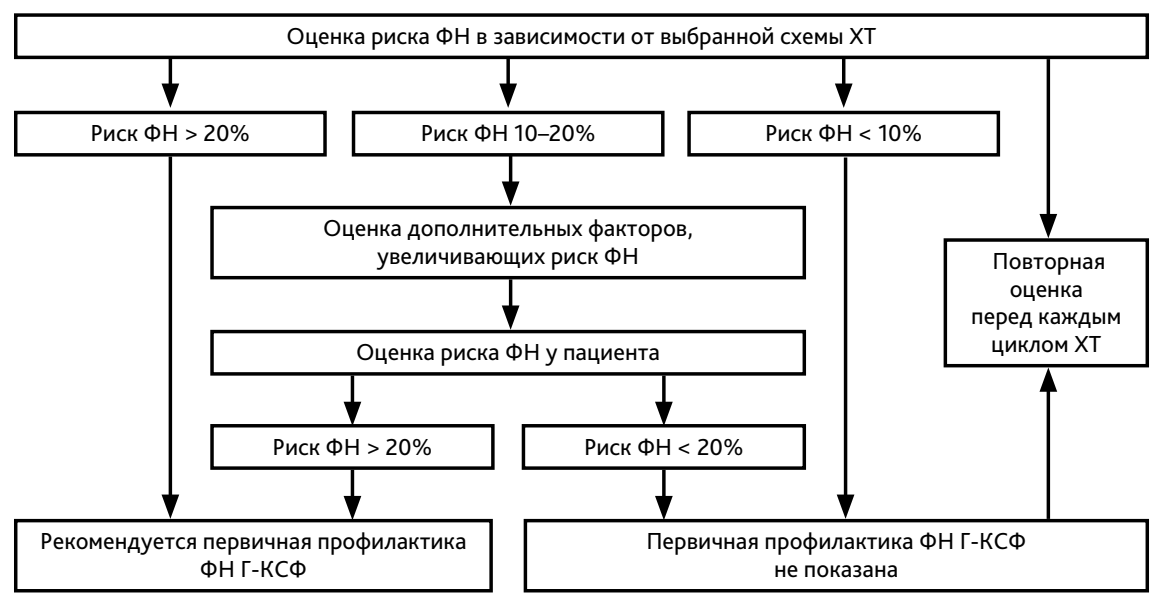

Рисунок 1. Алгоритм для назначения первичной профилактики ФН.

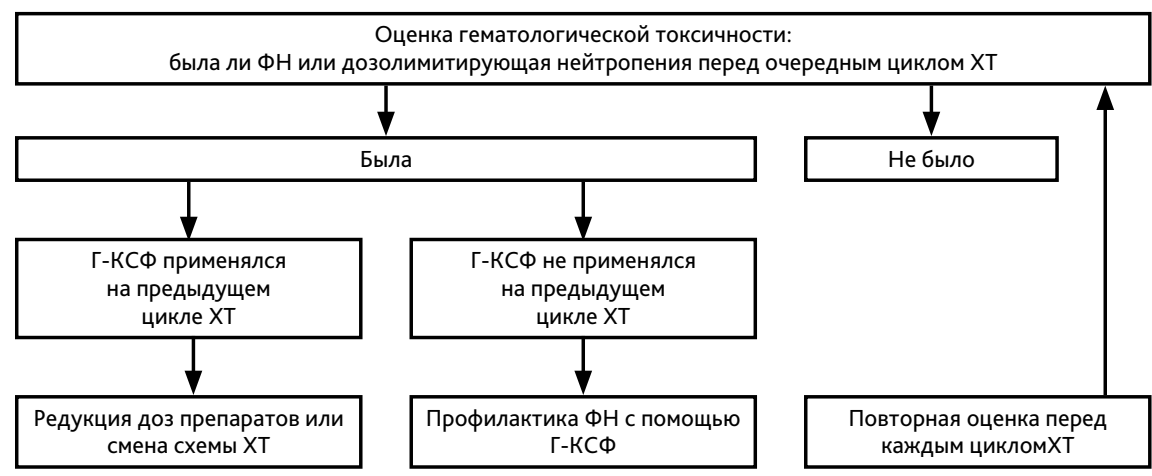

Рисунок 2. Алгоритм принятия решения перед вторым и последующими циклами XT. 